\title{
Anticipating the ultimate innovation, volitional evolution: can it not be promoted or attempted responsibly?
}

\section{Lantz Fleming Miller}

To cite this article: Lantz Fleming Miller (2015): Anticipating the ultimate innovation, volitional evolution: can it not be promoted or attempted responsibly?, Journal of Responsible Innovation, DOI: 10.1080/23299460.2015.1107019

To link to this article: http://dx.doi.org/10.1080/23299460.2015.1107019

Accepted author version posted online: 27

Oct 2015.

Published online: 16 Nov 2015.

Submit your article to this journal ¿

ЏII Article views: 6

Q View related articles $₫$

View Crossmark data $\nearrow$ 


\title{
RESEARCH ARTICLE
}

\section{Anticipating the ultimate innovation, volitional evolution: can it not be promoted or attempted responsibly?}

\author{
Lantz Fleming Miller* \\ Philosophy Department, City University of New York Graduate Center, New York, USA
}

(Received 22 July 2014; accepted 8 October 2015)

\begin{abstract}
The aspiration for volitional evolution, or human evolution directed by humans themselves, has increased in philosophical, scientific, technical, and commercial literature. The prospect of shaping the very being who is the consumer of all other innovations offers great commercial potential, one to which all other innovations would in effect be subservient. Actually an amalgam of projected technical/commercial developments, this prospective innovation has practical and ethical ramifications. However, because it is often discussed in a scientific way (specifically that of evolutionary theory), it first calls for examination in terms of common scientific approaches to evolution. Yet, as evolutionary-theory controversies point up, evolution may be considered as neither a directed nor a directable process - a problem for the ontology of volitional evolution. One challenge for theories and programs aiming to implement the proposed innovation is then whether it is theoretically coherent. While I offer responses to the challenge in the form of objections, these in turn remain problematic. Two central issues of responsible innovation arise: (1) If this prospect were feasible, would it be responsible to implement it, and (2) if it is not even theoretically coherent, is it responsible for innovators, even this early-on, to keep promoting it as if it were?
\end{abstract}

Keywords: emerging technologies; ethical responsibility; natural selection; responsible innovation; volitional evolution

The philosophical and technical literature has seen extensive discussion about the possibility of volitional evolution (Bostrom 2004; Hughes 2006; Harris 2007; Buchanan 2012). ${ }^{1}$ The concept is variously stated, sometimes as 'controlling' or 'directing our own evolution' (Bostrom 2004), ‘intervening in our evolution' (Hughes 2006), or even ‘breaking evolution's chains' (Buchanan and Powell 2011). I use E.O. Wilson's 'volitional evolution' $(1999,299)$ as the most succinct term. The concept seems to be that, as blind natural forces have shaped and continue to shape life, it should be possible for humans, using artificial means, to shape life into new forms as they see fit. Darwin (1952) borrowed the term 'natural selection' from the artificial selection used in horticulture. The recent 're-reversal' of the term back to an innovative type of artificial selection is commonly made with an eye on prospective technologies as the tools for humans themselves to effect a new, controlled selection.

This concept has both rhetorical force and metaphysical appeal. According to this concept, a plausible assumption is that, while human beings have been shaped by forces outside their

*Email: flemingmiller@yahoo.com 
control, they have emerged with at least a limited power and will to direct their own evolutionary destinies. They can use that limited power and will to take more control from the very forces that formed them. Humans should be able to overcome any natural limitations upon that will and thereby finesse more direct management of their own evolutionary destinies - seemingly both individually and as a species. The metaphysical appeal then, is that humans no longer have to be crushed by fate or blind forces but can chart out the very kind of agents they want to be.

As this feat is to be accomplished, in the current volitional-evolutionary context, by an assortment of diverse new technological innovations, it becomes the master innovation over them all, providing an organizing principle putting this assortment into a well-defined order and giving the consumer a potentially strong sense of direction and purpose. This paper's final question is whether such an ultimate innovation, if it were feasible, would be ethically responsible; and if it is not feasible, is it responsible to continue promoting it to the consuming public as though it were.

I must note preliminarily that while many of the current proposals for 'human enhancement', or more precisely, human improvement via emerging-techniques ${ }^{2}$ (HIVE) may characterize their goal as volitional evolution, not all HIVE programs do so. All those advocates who foresee a prospect of volitional evolution are not necessarily supporters of HIVE, either. The paper's concern, then, is with those proposals for HIVE that do characterize their ongoing program as that of volitional evolution. It then ends with a normative objection to such programs' use of this scientific terminology to characterize their program. It is not directly concerned with the ethics of HIVE programs per se, but since the discussion does bring in this normative element, it eventually assays the normative element - including why the paper upholds this element as so important - in light of some assertions that HIVE programs are ethically obligatory.

One further preliminary clarification about the discussion is as follows: There may be some concern whether volitional evolution is indeed an isolable, sufficiently singular innovation to warrant assessment of its innovators' potential ethical responsibility. It may instead seem to be a class of innovations, such as HIVE (with which it is often affiliated). It may also be seen as a bundle of innovations, rather than a single product. However, I believe that, if 'volitional evolution' were possible and is a category, then it is a more specific, narrow, and clear category of innovations than, say 'human enhancement' because it refers to a given objective scientific fact, that of natural evolution. Its promoters often contend that, now we have attained a level of technical development, we can effect this same sort of factual process ourselves. By contrast, 'human enhancement' is vague, referring to the subjective sense of what is better or enhanced, for which there is no precise objective scientific fact. (see Section 3.1) Even if there were objective methods for assessing the quality of a HIVE product, there is no one standard as to what is an enhancement, as there would be for what is a process of evolution.

Further, most innovations come within a category, and that abstract category may be as worthwhile for ethical assessment as specific products within it, or more so. Thus, in the case of volitional evolution, assessment of the category is especially dire because the innovation of volitional evolution - if indeed, commensurate with the scientific understanding of evolution - could well be one of the most powerful innovations yet, with far-reaching implications and ramifications, as evolution is the very process that makes us - the consumers - what we are. All subsequent innovations could well be subservient to it.

In short, for ethical evaluation of its potential implementation, volitional evolution can effectively be treated as a product innovation because it involves moral agents' undertaking deliberative action using an innovated product or products for the sake of achieving a discrete aim, that of evolving as a species being in some manner.

This paper is organized into three major sections. The first looks at what volitional evolution may consist in to see just what it may be referring to as a type of action. Here, many obscurities 
remain. The next section then puts the concept into the more specific context of evolutionary theory to see just what kind of evolution is to be effected in the process. Still, even in this more well-defined context, the concept remains unclear. As evolutionary theory is both complex and not unified within the biology community, this section is the most extensive. In the third section, I return to the question of whether in any case it is morally responsible to promote this innovation for the consuming public.

\section{Usage of a concept}

\subsection{A tradition of usage}

Many commentators advocating volitional evolution assert that it is continuing a longstanding goal, dating at least from Darwin, for humanity to take the reins of evolution into its own hands and dictate to nature what it wants to become (Bostrom 2008; Bostrom and Sandberg 2008). ${ }^{3}$ Darwin did, in fact, sometimes hint at such a perfectionist, directed evolution (and possibly volitional if in 'looking to' we are somehow participating in the process), as in the following:

As all the living forms of life are the lineal descendants of those which lived long before the Silurian epoch, we may feel certain that the ordinary succession by generation has never once been broken, and that no cataclysm has desolated the whole world. Hence we may look with some confidence to a secure future of equally inappreciable length. And as natural selection works solely by and for the good of each being, all corporeal and mental environments will tend to progress towards perfection. (Darwin 1952, 243)

In The New Synthesis, Huxley (1957) overtly propounded the concept of volitional evolution: 'The human species can, if it wishes, transcend itself ... in its entirety, as humanity ... the human species will be on the threshold of a new kind of existence, as different from ours as ours is from that of Pekin [sic] man'. (17) Whether Darwin and Huxley were correct in projecting humanity's perfectionism, the revolutionary formulation of evolution that Darwin helped formulate, via The Origin of Species, and Huxley to a lesser degree via The New Synthesis, has continued to be reformulated, expanded, and detailed. It is in this ongoing and expanding scientific context in which the concept of volitional evolution must be examined vis-à-vis the basic term 'evolution'.

Before exploring the ways in which 'volitional evolution' can be interpreted within the scientific usages of 'evolution', it is enlightening to inquire first into what volitional evolution could involve, as a concept in its own right and as a type of action, however the term is used in the sciences.

\subsection{The concept behind the usage}

Considering volitional evolution to be the umbrella term for the general concept of humans' directing their own biological evolution, the following should apply whatever specific term is used for the concept. If humans can now or very soon control their evolution as they may will, just as they may will to take a peach ice cream over the 30 other flavors in the freezer, it is germane to ask who is doing the choosing. Furthermore, what exactly are they choosing to do? A prima facie interpretation plausibly holds that the species Homo sapiens can now evolve into the next species - call it Homo supersapiens - just as H. sapiens evolved from Homo erectus. Only now instead of blind evolutionary forces, whatever these are, it is acts of will of the collective force of $H$. sapiens itself that accomplish the feat. The next question about this process is just how may the collective effort of $H$. sapiens accomplish this feat? Apparently, all 7+ billion (probably more by the time of any such program's implementation) somehow are 
to exert actions so that in a few generations, perhaps the next, their offspring will be the new species Homo supersapiens. If the evolution is to continue, as the whole concept seems to anticipate, the next species will in turn exert a concerted effort, ad libitum. If this is the interpretation that the concept's proponents intend (I doubt it is), it would require unprecedented cooperation by the world's population. Not only would all persons have to operate with an unusual synchrony to execute the program, they would have to agree to it. Perhaps this scenario is possible upon propagating duly convincing polemics and expensive educational programs training consumers in the evolution-causing techniques. However, little in the literature has given attention to the formidable practical and legal problems of implementing such polemicization, much less discussed the costs and the financial, political, and personal motivations for carrying out the program. One must consider why most people the world over would elect to make such an investment so that their future distant relatives could be a new species. This caveat is not to deny that a very convincing polemic could be generated. It is only to point out that this enormous unprecedented challenge needs solution to make the project feasible.

Most volitional-evolution proponents likely would not endorse this prima facie interpretation of volitional evolution. An alternative would hold that certain select leaders could be given the task of taking over the project, and the majority of the people would passively sit by and let the process proceed. However, either the polemicization problem remains, or those in charge will have to work their will upon the populations, who may well object. The latter choice may invoke significant political and moral problems (see Miller 2014b). Furthermore, this moral problem in turn poses more practical challenges: If the population dictatorially imposed upon rises up in violent rebellion, or the regime imposes its will no matter what, the outcome brings into question the whole structure and plan of the program. If it is to evolve a more peaceful or willingly cooperative $H$. sapiens than currently exists, it is founding itself upon a violent beginning. (Of course, if the program aims on generating a more violent species or one that cooperates without question or will, in this very program for violence or servitude it again runs into ethical problems that may be difficult to ignore rationally. Thus, the whole program becomes irrational and beyond the scope of the rational conversation that interlocutors apparently are attempting at this stage.)

An alternative interpretation is that volitional evolution does not really mean that the entire species shall evolve but only those who elect to do so. For example, a small group, perhaps of a few hundred colleagues, may meet and contract to undertake together operations $X, Y, Z$ upon their genetic structure. They also agree to isolate themselves and offspring for a few generations, until the genetic alterations have securely taken hold in later generations of offspring. These offspring can then remain sufficiently isolated from the non-altered population that they could safely be said to have speciated (see Section 2.3).

This scenario seems at least conceivable. However, it is apparent that those undertaking the evolutionary activity are not themselves evolving. They are not evolving at will but are exerting their will, upon others, to create a new species of those others. For some proponents, this fact may be of minor concern. But it is not clear that these people are doing significant evolution-control, unless they are content with a one-stop deal. They must as well design the new organism so that it willingly carries out yet another program to evolve new creatures from their grand-offspring. This scenario means some sophisticated genetic designing of the brain of the Homo superspiens - and ensuring that the latter species cannot reverse that brain-designing so as to block future volitional evolution. But then this feature means a reduced will of the volitionally evolved species; so they are no longer willing their own evolution. The program reaches a self-destructing inconsistency.

A related possible interpretation of volitional evolution is that it is individual human beings who may elect to evolve. Thus, agent $A$ in Italy one day elects to evolve, another time agent $B$ in Belarus does, and so on. The process transforms the individual into another kind of being that is 
not $H$. sapiens. Curiously, this scenario has fewer logical problems than the previous three discussed. It merely calls on the agent to lose sufficient critical portions of one's humanity so as no longer to be that species but, apparently, enough of an organismal identity tout court, retaining sufficient portions, so as to ensure that organism $B$ is indeed the thing changed. This stipulation may be thought of as one of Minimal Theoretical Reversibility; thus, enough of the former $B$ remains in $B^{\prime}$ so that $B^{\prime}$ could revert to $B$. The assumption is that if not enough of $B$ remains in $B^{\prime}, B$ is not becoming something else but has been completely lost. If all the particles of $B$ were to be placed into the middle of a blue star, $B$ would not become another thing but would cease to exist. However, even with this stipulation, it is difficult to say what $B$ is doing besides simply changing identity. At this point, then, it is time to turn to Section 2 to distinguish between scientific understanding of evolution vs. simply changing.

First, a final interpretation is warranted, which is to take some of the weight off the willingness and directedness of volitional evolution: The species, by gradually deploying, piecemeal, one form or other of new techniques and incorporating them more intimately and intrinsically into their lives, beings, bodies, minds, cannot help but in some way - one group bulging out this way, another subgroup stretching out that way - to become another kind of species. It is not a deliberate move toward a planned evolution. It is instead the operation of wills, willy-nilly, in the market place, as they opt for technique $T$ here, technique $U$ there, that lends them to potentially evolving into something else. This interpretation is disingenuous, though, and loses all the force of the volitional-evolution concept: It would not be humans controlling their own evolution but pursuing their usual species and cultural habits that just may (or may not) lead to evolution.

It is hard to see, in a preliminary non-technical sense, exactly how the project for volitional evolution is to shape up when translated into practice. Next I examine how the concept of volitional evolution squares up with the scientific notion of evolution.

\section{Volitional evolution in the context of scientific theories of evolution}

Like many technical terms, 'evolution' also has a non-technical usage. This fact, when context offers insufficient indication of whether the usage is strictly technical, can lead to confusion. The term 'evolution' is further complicated by the fact that scientific usages of 'evolution' are not as singularly or mathematically defined as those of other scientific terms such as 'energy' or 'entropy'. The concept of volitional evolution then demands examination in context of this fuzziness.

\subsection{Three major uses of 'evolution': with narrow or wide technical scope or non-technical}

To simplify the discussion, I focus primarily upon basic notions of evolution that are common to most current theories. However, one of the greatest challenges to doing so is to establish - or, at worst, to pretend there exists - a single, unified notion of evolution as a standard against which to measure any concept of evolution in general. One danger is making a version of a straw-man argument, establishing a notion of evolution that cuts across all theories and yet is cherry-picked and leaves no place for volitional evolution. I believe that danger is slight, compared with the challenge of finding a notion of evolution that satisfies most evolutionary theories. A similar concern is that in support of volitional evolution, one can always select those aspects of an evolutionary theory which seem consistent with volitional evolution, while inconsistent with the more ecumenical presentation of evolution which I aim to provide. Given these challenges, I can only leave it to the reader to judge whether this broader presentation sufficiently covers the common ground among theories. 
Within the scientific and philosophical communities debates abound concerning adaptation (Dennett 1995), exaptation (Gould and Lewontin 1979; Pinker 1997), teleology (Reiss 2009), developmentalism (Pigliccui 2001; Müller and Newman 2005), and other issues. Bringing these debates into this paper can only complicate its discussion without significantly affecting its point because in these theories the underlying concepts of evolution are what are relevant to the concept of volitional evolution.

Although many readers are well-acquainted with basic evolutionary concepts, I begin with foundational definitions to give the discussion a clear grounding and direction. First, in technical terms, evolution can have a narrow scope (focusing on small changes) or a wider scope (larger or long-term changes). Sometimes biologists define evolution, at its simplest, genetic level, as the change in allele frequency in a population. In other words, 'Evolution, at its simplest, is ... defined as any change in the hereditary composition of a population' (Savage 1977, 47). Such changes are often considered 'microevolution'. Divergent evolution or speciation requires microevolution, but not all microevolution - in fact, probably little of it - leads to speciation. Microevolution can be observed in the laboratory, but it is unlikely that speciation, at least through natural forces such as genetic drift, mutation, and natural selection of adaptive traits, will be seen in the lab soon, because these forces (at least in natural history) seem to operate over long periods.

Another, wider scope, technical sense of 'evolution' is of divergence: large, long-term changes involved in speciation. In fact, this sense is the more well-known technical notion of evolution as the process that, over eons, gives rise to new species. In turn, species undergo extinction, another evolutionary process. A species may predominate in large numbers for a period, then fade for a while, and possibly resurge or not. Unfortunately, 'species', perhaps more so than evolution itself, is not a well-defined technical term, although biologists still carry out their work successfully within a union of a large set of criteria that define most recognized species (Claridge, Dawah, and Wilson. 1997; Hey 2001; Pigliucci 2003). As evolution is an ever-shifting, neverending process in which all organisms participate, one may safely say that species-production is not a goal but a result of evolution. Species - certain populations of organisms in certain ways distinct from others as a type - are continually appearing and disappearing. Speciation itself may have resulted from certain contingencies in the way life originally developed, such as the reproduction of basic chemicals leading to life's genetic basis (Dawkins 1976) and hence the reproductive strategies (sexual and asexual) that developed consequent to this genetic basis (Baraclough and Herniou 2003). That is, this genetic basis of primordial life exerted a strong selection pressure favoring reproduction and eventually sexual reproduction, and these in turn further influenced the shape of survival and adaptive strategies in an ever-shifting (and so naturally selecting) environment. ${ }^{4}$

Besides these unwieldy but useful technical usages, 'evolution' has perhaps wider currency as meaning simply 'ongoing change of an entity'. Thus people speak of a child's evolving as it grows, a company's evolving in response to social changes, or an idea such as 'evolution' itself evolving over the centuries. An idea, child, or company is not composed of genes, even if the parts of some are composed partly of DNA (viz. humans being a part of a company). And while a child is composed partly of DNA, its changing as it grows is not evolution in the technical sense. ${ }^{5}$

\subsection{An ambiguity and attempted disambiguation}

Volitional evolution is ambiguous in terms of these various senses of 'evolution'. However, disambiguation leads to difficulties in all three senses. Start with the narrow scope of the technical sense, change in allele frequency of a population. If 'volitional evolution' implies 'volitional 
microevolution', the concept is feeble. One reason is that even the technical definition, while useful as an heuristic for assessing population characteristics in field biology and as an atomistic basis for explanations of larger, divergent macroevolution, loses strength when used out-ofcontext because of the vagueness of 'change in frequency' and 'population'. Secondly, human history (and probably prehistory) is peppered with conscious efforts at controlling gene frequency in populations, even if people in pre-genetics eras did not know they were 'changing an allele frequency'. A musically inclined person from a small musically illiterate town, in marrying a musical person and having children, may represent - if musical ability has genetic basis - an attempt to change an allele's frequency in a population. Movements of whites from mixed U. S. neighborhoods in the 1950 s and beyond were attempts to control the frequency of a population's melanin alleles, even if the moves were not overtly considered as such. As Ashkenazi Jews have a relatively high frequency of the gene for Tay-Sachs disease, the twentieth-century Shoah was an exercise in control of the frequency of an allele in the European population (even if the perpetrators did not intend specifically to control that allele frequency). Biologists have long noted that, because of the complexities of human culture, it is much more difficult to pin down certain concepts and their definitions which work well in the field for non-human species, so that the terms may be readily applied to human population genetics (Lewontin 1972, 1995).

Proponents of volitional evolution may be anticipating the control of human microevolution in terms of adding, say, to-be-discovered genes for intelligence or longevity. If enough people were to insert such genes into their somatic and germ cells, it may be said they would have deliberately altered an allele frequency in a population and so effected microevolution. If so, they have introduced a new type of technique for effecting microevolution. However, in the context of all prehistory, nothing new or outstanding would have been effected, no more than done by two musical persons' marrying one another, or whites fleeing blacks, in offering a new technique for effecting microevolution. Volitional evolution then would hardly be of moment, something humans and animals have been doing for eons without any notable change in the species or bringing about speciation.

More likely, considering, for example, the magnitude of some volitional evolution projects, the concept concerns divergent evolution. Literature on the subject often refers to humans inducing their speciation into a new species (Hughes 2006), anticipating how current humans, compared with a heavily altered organism derived from humans by HIVE, may one day seem like what an insect does to a current human (Vinge 1993). ${ }^{6}$ The implication is that, by humans taking evolution into their own hands, they would be controlling and directing future instances of divergent evolution. Resolving this issue, though, involves breaking it down further: Is volitional evolution looking toward speciation, macroevolution, or megaevolution? Some volitional-evolution proponents may be looking toward megaevolution several dozen or hundred years into the project, while more moderate volitional evolutionists may be looking only to speciation for the time being. In any case, any divergent evolution must go through the gate of speciation. It is useful, then, to investigate how volitional speciation can be effected. ${ }^{7}$

\subsection{Volitional speciation}

Speciation is the process by which new species appear. While the concept of species continues to be debated, species may, in the most widely accepted understanding, be considered as a population of individuals who are capable of interbreeding with one another to produce viable, reproducing offspring or who are otherwise isolated from breeding with other populations. A deme is a subpopulation of a species which is genetically similar and bearing a temporal and spatial relation' to one another (Savage 1977, 104). Individuals of different demes may at times 
interbreed with one another. But in time, one deme may become reproductively isolated from another; these isolating processes may lead to speciation. Some kind of isolation is a necessary but insufficient condition for speciation. The essential ingredients are some combination of: variation, selection, and genetic drift. ${ }^{8}$ If, among species populations that become isolated, a significant genetic variation is introduced, that variation is eventually selected; so it becomes endemic in the population, and if enough such novel traits finally preclude interbreeding of that population with others, speciation has some possibility of occurring.

Effecting control over speciation then requires effecting this process. That is, one must reproductively isolate individuals, introduce genetic variation, and have that variation naturally selected for until it is endemic in the population to the point that the population can no longer interbreed with other populations. Consider now someone who intends to effect such control. Preliminarily, this project could face some obstruction to population reproductive isolation because humans by and large extensively intermingle reproductively, especially now as modes of transport proliferate worldwide and expats grow commoner. The trend is overwhelmingly away from, not toward, such isolation in our species. Even isolated tribes in the New Guinea mountains are increasingly exposed to outsiders. If such groups were to make efforts to remain isolated, they are not those that most volitional-evolution proposals are explicitly targeting. In any case, a proponent of volitional evolution can object to this issue of isolation: (1) We could isolate either through new methods, such as free-floating artificial islands or space colonies; or (2) This isolation condition may not be necessary for further human evolution, as it is only contingent: In the past, this condition was that by which the process so happened to work, so that newly introduced variations had a chance to spread in such a way as to be different from the kindred group long enough to speciate. That is, what is important in isolation is giving variations a chance to catch on long enough that natural selection favors them and they become definitional of the new species, and such catching on can be achieved by other means at our discretion.

Conceding this interpretation of (the contingency of) reproductive isolation and the prospect that a volitional evolution project can provide the requisite genetic variation for change through biotechnology: The project then involves, say, injecting individuals with genes that are useful in society, such as genes for health, intelligence, and beauty (HIB). The next big step is natural selection. This 'force' may seem readily accessible to the project. Those individuals who receive the genetic boost are candidates for selection. If they thrive and reproduce, they will pass along their variation. If that variation proves so worthy over time, it continues providing fitness to generations; and if populations do get isolated (say in outer space), divergence may occur. Otherwise, we will simply witness a subpopulation expressing these genes.

However, problems arise for this scenario, vis-à-vis evolution: (1) This process is still not divergent evolution by microevolution and is nothing new, unless reproductive divergence does occur and those variations persist long enough (are naturally selected for) to form new species, which is still hardly a case of volitional evolution. (2) The injected genes may or may not prove to bestow fitness over the long range. Cultures, societies, and the physical environment change; these are the conditions that bring about the natural selection. As evolutionary history shows well, abrupt environmental changes may select against such highly specialized genotypes (Dasgupta 1995; O’Brien, Wildt, and Bush 1997).

But, the objection may continue, by noting that while speciation may not yet occur within the genetically injected population, such variation is a step toward the possibility of speciation. And, more importantly, the point of controlling our own evolution is that we control the environment that is doing the selecting. We create the sophisticated cultures and economies that require superior HIB (SHIB), and then we supply the genotypes for SHIB that can best fulfill such an environmental niche. 
However, it is important to consider what established the preliminary criteria for the cultures that esteem SHIB to such an extent that the volitional-evolution project tries shaping the environment to fulfill these criteria maximally. The evolutionary process over millennia shaped humans as biological and cultural beings with certain needs. In other words, humans to this point have been beings who have certain needs, and cultures are social structures that serve, in their varied ways, partly to express and fulfill those needs. A culture may not express or answer all of those needs for every individual, but without the organism and its needs, there would be no culture. Cultures supervene on human biology. They - as a human phenomenon as a whole are as much an outcome of evolution as is the biological organism. Criteria for valuing HIB (if not the criteria for beauty itself) are established and communicated through culture. Thus, the evolutionary process established the basis for these criteria in the first place.

The objection may concede, and even celebrate, the fact that evolution could then be said to have established not only these criteria, but the valuing for HIB as well. Thus it would seem that the project itself could be viewed as an outgrowth of natural selection. However, that conclusion would counter the volitional evolution project's very goal of wresting control from the evolutionary process to this point ('evolution proper'). That is, whatever is done in attempting volitional evolution is still done under the auspices of evolution proper. There is no intervening 'volitional evolution' that somehow breaks out of this process and sets out on its own. What exactly makes volitional evolution a distinct project then needs clarification.

\subsection{Bridging the classic gap between normativity and science}

Understandably, a further objection would be that, even if you do not want to call it 'volitional evolution', we take certain good qualities that evolution has given us, such as HIB, and emphasize these, while 'evolving out of existence' bad qualities, such as disease, fatuity, and ugliness. We simply refuse to take everything evolution has handed us. Where formerly it selected traits, we now do the selecting - of the best qualities it so happened to provide us. We please everyone by maximizing these qualities across cultures (to minimize differences in criteria of, say, beauty or intelligence).

However, the introduction of the normative criteria 'good' and 'bad' into the discussion creates a further difficulty, to which I return. A volitional-evolution program may anticipate any difficulty here by preempting it, by maximizing the qualities across cultures for widest possible appeal - that is, for maximizing 'good' over 'bad'. But this move would only corroborate and compound the problem: Introducing the 'good' and 'bad', as well as the issue of maximizing what are most widely considered good qualities, not only assumes that 'good' is what receives the greatest number of votes, but also confirms that some people may not approve, or that the project is trying to gain everyone's at least minimal approval. Simply, the proposal signifies that approval is sought. And yet, if approval is not gained, by unanimity or plurality or majority, then what? The project is trapped not in a scientific but a normative quagmire. No matter how much the project asserts 'Everyone wants to get rid of fatuity, disease, and ugliness', the problem remains that, now that these are deemed 'bad', the criteria for them are not clear-cut and some people may not approve. At best the criteria can only be approximated by the sort of computer-assisted blends of human faces that derive the optimal fit that pleases the most people and offends the fewest (Jones, Little, and Perritt 2003). Yet, while one blended face may please the most and offend the least, it may not much fulfill anyone. The project for volitional evolution appears to require mass approval of particular normative criteria in order to make the next step, that is, evolution by (unanimous?) global vote, which is cumbersome at the least.

A project supporter may concur that such a scenario is absurd and is hardly intended. ${ }^{9}$ There are a couple of possibilities for diffusing the need for such a scenario; 
(1) Such voting is simply not even germane to the system: People are naturally geared to long for SHIB by certain universal criteria for which evolutionary psychology can avouch (Etcoff 1999). In this way, the project can circumvent the accusation that it creates a normative quagmire and thus puts the program back on a scientific basis. Such a tack, if seamlessly achieved, might indeed result in the world population's unanimously and voluntarily conceding, without official votes, to accept a type of change in their physiologies such that these all conform to certain theories of evolutionary psychology concerning criteria for human HIB. This scenario is assuming that evolutionary psychology will one day conform normativity - across all cultures - in such a way that all persons would voluntarily accept the discovered criteria, drop any inferior practices, and conform themselves. But this rationale for volitional evolution is subject to two further problems: (a) A logical problem: It is left once again with a paradox, viz. that in taking our destinies out of evolution's hands, this destiny still ends up being entirely shaped and dictated by evolution-till-now, which the project aims to transcend. (b) A moral problem: It creates a relatively homogenous population conforming to an idealized prototype, carving off the messy, large fringes that evolution has carelessly included. To preclude such an outcome, the project may try to build-in a device to avoid such homogenization. Thus, either the program as it unfolds would disallow homogenization and so preclude this option of unanimous volunteerism as a way to retain volitional evolution, or homogenization would indeed result and would make for a significantly undiversified population, leaving the population susceptible to environmental fluctuations and thus posing a moral problem for those who would thereby direct the population.

(2) The second scenario for avoiding the absurdity of evolution by global unanimous vote: One aspect of our taking our destinies out of evolution's hands is taking control of the environment that gives rise to cultural criteria of HIB. We no longer allow the haphazard environment which has formed and shaped evolutionary outcomes and in turn formed and shaped culture. We build domes over cities or shields against asteroids or construct entire planets, of which, say, every molecule and atom is put in place by nanorobots. In short, we ensure that the environment is constructed in such a way that it favors only positive human traits, such as HIB, and disfavors the bad ones. This way, whatever selection which does occur via environmental influences will be favorable; and furthermore, social selection will persevere as a strong force. However, I note that this second option has problems similar to the first: (a) A logical problem, much like the previous. Although the aim is to take our destinies out of evolution's hands by thoroughly controlling the environment, the requirements for that environment and what counts as favorable in whosever lights have been set by evolution-till-now. Thus, this destiny still remains entirely shaped and dictated by evolution-till-now; so no destiny has been taken out of evolution's hands. (b) A moral problem. This problem includes not only one like the moral problem for the first option, in that the cultural diversity will be severely defined and diversity constricted. There is a further moral problem in that such constriction may well come off to many members of the population like oppression.

The objection here harks back to an earlier point and concedes that volitional evolution is indeed normative, if based upon a scientific notion of evolution-up-till-now (as if humans have reached a high juncture on an evolutionary tree). By the very promotion of the innovation as volitional, there is indeed normativity in the project's enjoining others to join this project as the optimal choice for humans. The project's scientific basis lies in its recognizing the process of evolution-till-now. It grants that evolution has molded and changed organisms until now, that this process stands as the model and inspiration for further change in the structure and adaptability 
of beings, but that this change will now be done in a different manner. Thus, criticizing the project for being normative and hence not scientific at its basis misses the project's entire purport.

However, this objection only concurs with the view that volitional evolution is not actually a concept of evolution as scientifically understood. Perhaps it is inspired by the story naturalists have constructed of a nearly 4-billion year process of generating a range of beings and beingtypes. Perhaps with this inspiration, a volitional-evolution project may propose to create its own range of beings and being-types. But this proposal for such a creation cannot be, as the discussion so far has revealed, 'evolution' in the current scientific understanding. The project proposes something else, and it would be clearer, in scientific contexts, to use a term other than 'evolution'.

\subsection{Beyond (and beneath) the planet of 'scientific' evolution}

The objection as to whether there is a significant problem with the concept of volitional evolution would maintain that the worry about previous biological evolution to any extent is wholly beside the point: All that is meant by 'evolution' is the broader sense, that of change. It is not relevant whether evolution-till-now shaped and dictated everything that we are, including our desire to escape its clutches. We simply want to take all our future big changes into our own hands and be the ones controlling those. ${ }^{10}$ Besides, if we take one proposed option, uploading our minds into computers (Chalmers 2010), we will not even be genetically based anymore, then whatever changes we do impose upon ourselves and our destinies can no longer be defined by genetics or dictated by selfish genes. In that way, we transcend our pasts.

As for this line of objection, either (a) The 'evolution' of volitional evolution then is the quotidian sense that we use every day and has always been the case, in that we seek control over the changes in ourselves. Thus the project usage of 'evolution' does not convey the intended scientific impact and, despite its users' intentions otherwise, cannot reach beyond the common usage as mere 'change', or (b) The project's usage of 'evolution' is to gain, by association, the cache of scientific 'divergent evolution' even if lacking the appropriate details and facts. But then, as to precisely what the future details and facts may be, support for volitional evolution must resort to something like: "Whatever our kind of "evolution" will be, it will be more impressive than the old version and will be fashioned by our own wills and production methods'. But, lacking scientific basis, this reply would only fall back into an obscurantism that I doubt the volitionalevolution advocates would want.

However, to maintain scientific stature for the project, the final objection is to note that this whole discussion is contingent merely upon current scientific understanding of 'evolution'. As scientific theory itself evolves and becomes more powerful, it may well incorporate the concept of 'evolution' that project supporters invoke and then make the project scientific. Yet, to bank on what a science may become, so that a concept currently outside mainstream science may later become scientific, is taking a large gamble. (Similarly, one might hold that any concept, such as the powers of Baal or the influences of Jupiter on Aquarius, may one day be scientific concepts.)

I should speak to another possible interpretation of 'volitional evolution' that holds this notion not as continuing evolution understood in the scientific sense but as deliberate operations upon the human genome, body, and brain that transcend the scientific modes and definitions of evolution, even including that of the human being as a biological species, $H$. sapiens. Some HIVE promoters may intend such a broad interpretation. There are a few drawbacks to this interpretation of 'volitional evolution'. One is that, while expressly not the scientific usage, it is still too broad and imprecise to merit as a substitute for the scientific usage. It may seem that, if HIVE projects were indeed realized and many of these techniques were successfully marketed, halting 
evolution-as-it-is-known for human beings' future generations, there might be a call for a scientific inquiry into the nature of these entities and how one type may serve as precedent to another type. However, even this sort of after-the-fact scientific taxonomy would be superfluous or worthless because in this context of HIVE, the sciences are understood as underlying and informing the techniques; so in the production of HIVE entities - since developers, including late-generation autonomous robots' creating entities, are not producing entities randomly and haphazardly - it is already understood what kind of entities are being produced and where they fit into the overall HIVE scheme. At best, a taxonomist would serve in a kind of historical pursuit, much as museum taxonomist classifies makes of rocking chairs or adding machines.

If human beings or the entities that some of them have made have not eliminated all other life forms, there would still be biological evolution, which would reflect the current scientific meaning. For whatever human-based or human-invented (or human-invented-entity-invented, etc.) entities that remain, if they have indeed halted evolution of beings derived from humans, they have in any event halted human evolution. Other biological species may still exist, but (certain) human beings possibly would have disallowed humans to remain human and evolve biologically. HIVE promoters intending to offer 'volitional evolution' should make such clarifications as I am suggesting as to what they intend or envision and be more exact than waving hands and speaking vaguely of 'transcending' biological evolution and redefining 'biological species'. Otherwise, 'volitional evolution' as transcending evolution simply reflects an intention to halt evolution and methodically produce entities based on the human being (at least initially), but changed somehow. 'Volitional evolution' then reverts to merely some kind of change 'Biological species' is not redefined but stays intact if non-human evolved lifeforms such as mussels and sparrows are still allowed and people are allowed to remain human and not alter themselves or their offspring according the HIVE guidelines.

'Volitional' in this context of intended redefining evolution and biological species offers a further poignant drawback. There is a lack of clarity in who exactly is willing the 'evolutionary' effort. Individual consumers, making whatever changes they want? As noted above, that scenario appears to lack the coordination that orchestrated change of the species would require. Or rather, is the 'we' of 'we now control our evolution' a coterie of industrialists and government who decide for the population? The prospect of tyranny looms. 'Transcendent volitional evolution' at this juncture promises to be not transcending anything but possibly disposing of something valuable, and not attractively volitional if volitional at all, and not evolution.

\subsection{Volitional evolution's need for clarification}

The 'evolution' in the concept of volitional evolution cannot be microevolution, divergent evolution, or speciation in the scientific sense of these concepts. Furthermore, an innovating project based upon this concept evidently cannot sidestep the very evolutionary process that it aims to take control of or to transcend. More broadly, since the evolutionary process is apparently going nowhere, ${ }^{11}$ attempting to direct a process that is intrinsically non-directable is highly problematic. The one sense of 'evolution' that leaves the concept of volitional evolution intact is the sense of evolution as any change, which is not a momentous sense. ${ }^{12}$ While I have not resolved the problem of volitional evolution's ontology in terms of solving it, I hope I have resolved it to the extent of increasing the resolution or the detailing of the problem in terms of what kind of changes are projected to be in store for present and future people. The work ahead is thus now laid out for clarifying just what kind of change that the prospective innovators are attempting. As the fully implemented innovation of volitional evolution is projected to trigger - or would have the effect of - historical upheaval, the clearer the details of the pivotal concepts, the more 
clearly we can project, examine, and discuss these futures. Such clarification should thus help resolve the strong controversies surrounding such possible future innovation.

\section{Volitional evolution and responsible innovation}

To sum up so far, this article's major normative concern arises from the very notion of volitional evolution, which is fraught with conceptual and ontological problems. Proposals to effect volitional evolution will not effect evolution in the scientific sense; at best they may merely halt the evolution of species from $H$. sapiens. Given this fact, HIVE projects seeking to alter the species according to someone's idea of improvement and terming the projects 'volitional evolution' mislead potential consumers, whether promoters are aware of the deception or not. To give them the benefit of the doubt, we can assume they are unaware of the deception, and therefore are not involved in fraud. Because of the seriousness of the matter - the aim to capture consumers at the very root of what kind of being they are - and the exceedingly powerful notion of someone's controlling the very essence of that being by conquering nature entirely and wresting the process of evolution from it, it is time to reframe such projects as other than volitional evolution.

This normative objective may potentially be challenged by the need to weigh it against the ethical analysis of proposed HIVE projects themselves. That is, on one hand there is this article's normative concern with the precision of 'volitional evolution' in this scientific context. On the other hand, there is a broader normative issue as to the ethics of such projects themselves. As for whether such projects are ethical, ethicists range from approving to disapproving. What if these projects are actually propitious and thereby ethically obligatory, would not this article's worry about a term or concept used by only some HIVE advocates be minor, if not digressive? Even if 'volitional evolution' is indeed misleading, is not a little deceptive advertising virtually acceptable, given the good that may come from the projects? This further issue is worth consideration before discussing responsible innovation in terms of volitional evolution.

\subsection{Related normative issues concerning HIVE and volitional evolution}

Some philosophers have proposed that consumers are morally obliged to purchase and deploy HIVE products. Savulescu (2001) contends that parents-to-be are morally obligated to use preimplantation genetic diagnoses to weed out bad traits and emphasize or add good ones, even if these measures further abet social inequalities. Buchanan et al. (2000 persuasively argue that it is ethically incumbent upon human beings, for improved public health and health-care programs, as well as personal choice and freedom, to reconfigure the human genome, heightening good traits and eliminating bad, so as to maximize human wellbeing. Contrasted with Savulescu, they seek to diminish social inequalities through proper genomic control. Savulescu and Buchanan et al. share much with Fletcher (1988), who contends that evolution and sex over the past four or so billion years have been sloppy ways to make beings, such as sapient, conscious, intelligent $H$. sapiens, relying as evolution and sex did on chance mutation to take the next baby step in the evolutionary line leading up to humans. Now human intelligence can and must seize careless, amoral evolution and replace this toxic rule of chance with sober, compassionate reason, which can do a better job.

While these different ethical exhortations to human reason in order to fashion a morally acceptable creature based upon the human genome take slightly different angles, I try to respond to themes that run through them all. I begin with the mildly problematic worries about these thematic approaches and work toward the more deeply worrisome. 
One matter is a recent upsurge in inquiry into whether it is ethical willingly to bring a sentient, conscious, intelligent being such as a human into existence in the first place (Shiffrin 1999; Benatar 2006; Overall 2012; Miller 2013b). The problem of bringing a sentient being into existence is that the being will experience harm, so such an act is essentially creating harm for that being. I am emphatically not advocating this view but bringing it up as one ethical challenge for HIVE projects to handle. They must either (1) make the entities they plan not fully sentient; so they do not experience pain of any sort and thus cannot be claimed to having been harmed by being brought into existence, but then without full sentience they may lack some of the interrelated traits of consciousness and intelligence; or (2) do harm by bringing these entities into existence.

Another challenge is that of commodification of the individual. Not all HIVE promoters, particularly certain types of Libertarians, would be much concerned about commodification of any kind, but it should at least be considered. Currently, agents even in industrial societies have the freedom to choose to minimize their role as consumers. They are still free to denounce and partly renounce the highly resource-intensive culture about them and strive to avoid commodification of their lives and of life itself. However, entities fashioned by genetic manufacture, even if government played a role alongside industry, would make that entity a commodity tout court. Being a commodity leaves one little place to opt out of commodification, and thereby a freedom is lost. One becomes much more enthralled to the industry/government amalgam. It may be objected that the globe is so beholden to the industrial/governmental amalgam anyway, it is only a small step for individuals themselves to become commodities. We should consider, though, that this step may be small for some individuals, but it would be a giant catapult for humanity.

One of the most indelible problems with arguments that HIVE is ethically obligatory is that of value assignment. Buchanan et al. (2000) touch on this issue, but not from the angle I provide momentarily. Hauskeller (2013) goes into some detail, and I refer readers to it for complementing what I say here. The HIVE-as-morally-obligatory argument depends upon some shared theory of the good, of what sorts of human traits are good. Either the entire population holds this theory, or subsets of the population do. The latter case allows the kind of 'diversity' in HIVE entities that may eventuate. Some groups may highly value super-intelligence, moderate statures, and empathy; others may value emotional response to music, intensive sexuality, and religious tolerance. The first problem here is that what is allowed to be good within subgroups must still face a higher level of value assessment above them that determines whether their subgroup valuing is indeed morally permissible. For example, a subgroup may cultivate a type of racism, say a genetically founded hatred of entities who have emotional responses to music. Or, with less blatant value transgressions, a subgroup may cultivate an intolerance for people who highly value intensive sexuality. In any event, there would have to be in place an authority over the subgroups, determining whether their values for fashioning their genetic engineering abide by a greater set of values, and so we are back to there being a universal set of values for genetic engineering outcomes among subgroups. Then the problem looms of just who is to determine those 'universal' values, and who is to enforce them.

At a more personal level, there are further valuing problems. Either (1) subgroups fashion their new entities within strict genetic guidelines, or (2) they allow some slack. In the first case, someone in a subgroup genetically implanting chemistry ability and tallness will just keep producing new entities like a gene mill in perpetuity. Rigidity threatens. In the second case, with some slack, a new entity to this subgroup may long to be a composer, but genetically lacks the capacity and lives a life of regret. Should there then, for slacker-allowing groups, be inbred anti-regret genetics so as to prevent such painful lives? Again, then, the prospect of eliminating all kinds of pain, even regret and sense of outrage and injustice, looms. The enterprise 
starts losing its allure as one creating entities of improved moral character. ${ }^{13}$ (Hauskeller 2013 provides a detailed argument for why the issue of valuing leads to inconsistency and incoherence in terms of attempts to better humanity; I refer the reader to that work to explore further this issue of valuing.)

Another deep concern is that of human rights. Much HIVE-as-morally-obligatory arguments at least imply that to be consistent with human rights, parents are obliged to make their children as genetically best as feasible within current technology. Human-rights documents so far have no wording about people's having the right to the best genes as possible. (For one matter, implied above, is that what 'best' may consist in could vary widely culture-to-culture, and cultural value may place as 'best' that which is not interfered with by technique.) Incorporating the concept of right-to-best genes would require reworking human-rights declarations as well as basic concepts about humans. Amending such documents per se is not the greatest challenge here; the problem lies in thereby steamrolling over other extant rights. Human-rights theories and declarations have built upon the foundation of what the human is as a particular kind of being. If having the 'best' genes possible were to become a human right, and that were considered a universal right, then we could be railroading over human rights to reproduction, to assembly and personal relations (as freely pursued sex would be outlawed because it could endanger offspring's acquisition of the 'best' genes), and to group rights as guaranteed by United Nations Declaration on the Rights of Indigenous Peoples (UNDRIP, United Nations 2007) - since many groups the world over have opted not to join industrial culture, and UNDRIP guarantees them that right (Miller 2013a, 2014a).

While many HIVE promoters have allied themselves with political Libertarianism, ensuring HIVE's materialization leads to possible totalitarian outcomes. If the moral obligation of providing the 'best' genes were no more obligatory than telling at a party a white lie about the color of your natural hair, then HIVE-as-morally-obligatory could escape some of the objections raised here. However, it is implausible that a moral exhortation about not harming a new being (by not providing the 'best' genes) is no more serious than such a white lie (pace Kant). In the literature are hints that such obligation could in fact be legally enforceable - and thus the objections I lay down remain intact. The human race, facing such an enforceable law to apply to all human beings, also faces the issue of who is the 'we' controlling what the human race is to change into (Miller 2014b).

\subsection{Conclusion to related normative issues concerning HIVE and volitional evolution}

At this juncture, it would be most responsible for hopeful HIVE innovators and their promoters to recognize that HIVE projects are not 'volitional evolution' and eliminate the concept from project promotions. HIVE advocates could then most clearly represent their projects as the acronym itself implies: The projects intend to deploy techniques now available or anticipated to be available within a few decades expressly to refashion the human form such that those alterations mark what, for the inventors, are improvements. In its publicity, HIVE advocacy would most responsibly admit that the prospect of universal 'betterments' of this sort to the human form is fraught with problems of: (1) how extensive these alterations will be enforced upon the human population, whether de jure or de facto; (2) who exactly is the 'we' who is going to determine these alterations upon the human form; and (3) the fact that 'betterment' is much more elusive and paradoxical, in terms of realizing it on the human form, than this enticing term would lead one to believe (see Hauskeller 2013, 2014; also Agar 2010). In short, less zealous salespersonship is needed and in its place more sober, analytic, commonsense philosophical examination - in the analytic tradition - of terminology and the presuppositions, logic, and argument based upon it. 


\subsection{The ethics of promoting volitional evolution}

If we are to take seriously the responsible-innovation idea that 'every decision an engineer makes has the potential for ethical implication' (Hoople, forthcoming), then even decisions at preliminary stages, such as those at which volitional evolution has now reached, along with techniques presumed to enable it, warrant ethical consideration.

Certainly volitional evolution would not be a single innovation but a set of interrelated innovations that would contribute to and possibly be promoted as constituting volitional evolution. Because of this unity in direction and presumed outcome, it has been useful in this article to consider these as a single innovation. The previous discussion has brought up some normative issues arising from such innovation and its promotion. Considering that entire discussion and the conceptual problems it brings out in the general volitional evolution program, these difficulties bring up further normative concern for responsibility in attempts to implement these programs.

Anticipating such an ambitious innovation as volitional evolution with an eye on assessing it ethically brings up the degree to which innovations can be sufficiently anticipated in terms of ethical assessment of them (Guston 2013; Nordmann 2014; Wilsdon 2014).Without going into this debate, I should point out that one upshot of Section 2 is that we indeed cannot anticipate this conglomerate innovation of volitional evolution because there is a good likelihood it is simply misconceived. However, even if it is misconceived and cannot be realized as its promoters promise, I shall argue, there is still a concern about the ethical responsibility of promoting it.

First, I start with the possibility that the analysis in Section 2 is incorrect and one day not too far off humans will be able to will the evolution of new species from humans. To simplify this discussion, I narrow down the possible scenarios to that in which some humans, particularly technical innovators and industrialists, devise methods by which consumers can either themselves evolve into new species; so their offspring shall be new species, or only their offspring are new species. One concern of ethical responsibility is whether parents of one species can properly raise children of a humanlike although markedly different species. This problem echoes the bioethics worry about raising offspring 'more advanced' than oneself. Solutions seem at least conceivable, as not only may the adults have selected their offspring's traits and have some advance knowledge of what to expect, but concerted community efforts along the same lines could offer needed help. More daunting is the issue of whether one can, in an ethically responsible way, fashion a new creature who may well have rights and emotional and material needs unpredictable from the parents' lives or from the projections of what kind of being is created. This problem may be more readily soluble for the case in which the parents have chosen to be that different kind of creature and so have some idea of this existential challenge. But in cases of making one's offspring (or by whatever other route) new offspring, I see no such ready out. Nature is not a moral agent and cannot be held liable for the organisms that arise from its mix of forces; so we cannot blame nature for creating H. sapiens or Drosophila melanogaster. Humans are moral agents and would be culpable for any Homo supersapiens or other new species.

Another problem is whether there can be a coherent society composed of different species, some of which may have been designed specifically to outstrip competitively those already existing. Proposals to keep strong 'ethical' checks on what is created form one response to the challenge, although it is not clear if one can indeed anticipate the ethical problems that could be encountered and thus ethically build-in the proper limitations (Nordman 2014). More tantalizing is the fact that human societies are structured on human needs and answering these (which may partly account for why humans have such difficulty being good stewards of the planet's other species because these, with the exceptions of animals domesticated to live in human society, do not with their peculiar needs fit well under the human social umbrella). The new species 
may well have to establish a new society - but where? Other planets? There is the significant problem of how to establish their society before they come into existence or at least reach adolescence, so they will have somewhere to fit. But without already having somewhere to fit, it would be very hard to draw up with due ethical responsibility a sociopolitical plan that could properly accommodate them. And there would likely be more than one new species, as consumers across the world, given usual call for freedom of marketplace, would want their own design of new species. So the problem of responsible sociopolitical design multiplies. Even if only some consumers across the globe elect to evolve or have offspring of a different species, a further consideration is due. Because of these unprecedented problems of how to fit the species into the society or a neighboring society accommodating their needs, other consumers in the world community particularly those not choosing volitional evolution - would be markedly affected by those consumers' electing volitional evolution. The stakeholder approach to product development (Freeman 2008; Blok, forthcoming) and the impact such innovation may have on the world community add further incentive to question whether volitional evolution can be responsibly implemented.

This innovation's proceeding as planned poses significant challenges for responsible innovation. But there are also challenges for the anticipated innovation if it is indeed misconceived as Section 2 argues. Currently, volitional evolution's supporters seemingly assume that the innovation is a valid possibility. However, now that the case has been made that volitional evolution is misconceived and does not sustain as an ontologically valid possibility, it is up to promoters to answer these challenges to their anticipated innovation. If promoters cannot offer a sound justification for why their innovation is indeed bona fide evolution, then their product innovation would be improperly characterized. For example, if innovators offered a product as a specific innovation of volitional evolution, by which consumers could replace their bodies entirely with prosthetics, the product would in fact be misrepresented as volitional evolution, since such an innovation would have been shown to be ontologically infeasible. In this case, then, the ethical consideration is that of untruthful marketing, when the falsehood behind this marketing is known. It would be comparable to offering a scientifically bona fide time-traveling device when or if it had been shown that time travel was not scientifically conceivable, within the scientific understanding at the time. Such a case could even merit the label of fraud (if indeed the marketer knew of the scientific invalidity but proceeded to market the product as advertised anyway, fraud requiring deliberate, knowing deceit).

Thus, in any case, whether or not volitional evolution is an innovation that falls within the scientific notion of evolution, it poses serious problems for responsible innovation. If it proves to be a scientifically valid innovation and consumers can indeed create scientifically bona fide new species from $H$. sapiens, there are serious problems for how the product could be implemented with due ethical responsibility. Such responsibility includes that toward the newspecies offspring, as species until now have been brought about by other than moral agents, because nature is not a moral agent. The responsibility also includes that toward members of society-as-it-is, for whom there is no necessity in there being newly, deliberately evolved species without their asking for such interference with their lives and social structures. There is also responsibility toward the new species' themselves, for whom the new society would face a serious possibility that it did not fit their needs. By contrast, if the innovation is indeed scientifically and ontologically misconceived, as this paper's first two sections argued, there remains the ethical responsibility in dubbing products as those of volitional evolution - false representation at best, fraud at worst. If volitional evolution is indeed neither a scientifically nor ontologically valid prospective innovation, the whole engineering ambition to realize volitional evolution would best and most responsibly be dropped. 


\section{Notes on contributors}

After attending Massachusetts Institute of Technology and Columbia University, Lantz Fleming Miller completed his $\mathrm{PhD}$ in philosophy at City University of New York. He has published a number of articles and reviews in social and political philosophy and applied ethics and is at work on a book on a naturalistic analysis of equality. He currently teaches applied ethics.

\section{Notes}

1. The concept also appears in numerous works by non-philosophers and non-scientists such as journalists, as in Radical Evolution (Garreau 2005) and Designer Evolution (Young 2006).

2. 'Emerging techniques' are widely considered to be those of 'high technologies', including bioengineering, genetic manipulation, cognitive pharmaceuticals, artificial intelligence, brain/computer interfaces, and sometimes cryogenics as a method of prolonging a person's chances to take advantage of future developments.

3. Hughes (2006) notes that a very similar concept predates Darwin, at least as far back as Denis Diderot in his work D'Alembert's Dream. Diderot argues that the mind/brain could be deconstructed and reassembled in a different medium than its present one, and that by technologies people should be able to bring the dead back to life, restructure animals and machines to make them intelligent, and redesign humans themselves into entities 'whose future and final organic structure it is impossible to predict.' (70) Other recent writers have made comparable assertions of historic roots for humanity's seizing control of its own form, essence, and destiny so that these may be completely manipulated; see Bostrom (2005).

4. See Dawkins (1976) on the extent to which reproduction was a necessary condition for evolutionary adaptation even to occur.

5. However, see Müller and Newman (2005) for whether development serves as a source of changes upon which evolution may operate, in a developmentalistic approach to evolution.

6. Note that not all literature in this area anticipates speciation from humans; Kurzweil (2005) maintains that posthumans, or those who follow his suggested methods, would still be human. Because this particular proposal does not appear to involve volitional evolution, it is not relevant to the present discussion.

7. I leave aside the complication of 'chimeras', or organism types manufactured by the mixture of genomes of two or more species, such as a chimpanzee blended with a snake or a giraffe with a robin. It is still not clear that such organisms would be new species, for the same reason as associated volitional evolution proposals discussed below. Besides the fact that it unclear how feasible such blends would be for yielding viable, reproducing organisms, the proposal faces reservations as to the ethical justification for the experimentation on animals needed to produce such organisms.

8. Genetic drift, a third force in evolution, involves the introduction of neutral or nonadaptive traits into a population. See Pigliucci and Kaplan (2006) on whether genetic drift and selection are indeed separate.

9. However, Bostrom (2004) proposes a system of globally controlled evolution but without mentioning these theoretical and practical problems of attaining normative consensus or the moral consequence for dissenters.

10. The point here is that HIVE proponents promoting their programs as volitional evolution can meaningfully do so only if the sense of 'evolution' used therein is the common, non-scientific sense of simple change of any sort. This fact that volitional evolution can be meaningful only if 'evolution' is understood as the common one of simple change of whatever sort is not to be taken as trivial, but only as non-scientific.

11. In the philosophy of biology literature, especially in light of the adaptationist program, there has been extensive discussion about whether evolution can be teleological (Reiss 2009; Depew 2011). The controversy concerns the degree to which evolutionary adaptations define species and organisms. As Reiss put the problem: The observation that an organism would not exist if it did not have a certain trait is no justification for asserting that the trait appeared because it had this beneficial character. Otherwise, in the final picture appears the common one of evolution's pulling the mass of organisms, over time, in a certain direction (a tendency in thought even Darwin exhibited; see his quote in Section 1.1.). In the scientific context, evolution is not going anywhere; the mass of organisms is not working at becoming a certain sort of thing. Not only would this sort of teleology, in evolutionary terms, be irrelevant, but 'directed evolution' would be an oxymoron. 
12. Further considerations for proponents of volitional evolution: (a) How can we know what 'evolved' needs we will have in the future, based upon what we think - or interpret - that our current society is and its requirements vis-à-vis our evolved state? (b) How do we know that whatever our society may be in 200 years will have vastly different needs? (c) How can we know about vastly different changes in the physical environment that can come about, which evolution has dealt with in its own way in the past? (d) How do we know what to direct ourselves to be if we do not even know ourselves or know what we are? There is a kind of embedding problem here: We always have to know more now than we know in order to do undertake volitional evolution. That is, the horizon ever recedes.

13. Some observers may protest this objection, saying 'What is bad about eliminating all kinds of negative experience, from pain to grief to regret? Why not just engineer indelibly, irreversibly pleasure-experiencing entities?' The argument involved here is extensive. One simple, if flawed, argument is a reductio, concerning whether one can eliminate all negative experiences. Say you eliminate all previously considered negative experiences, such as pain from breaking a leg, grief from losing a parent, regret for not having gone to the bar last night to meet friends, or outrage from injustice. Now you have a new set of a range of experiences. Some are not as good as others; so by comparison, they are negative, and they must be eliminated. And so forth. One can thereby never find good experiences. This reductio could be refuted by saying that not-so-good experiences are not necessarily bad; one just has a new scale with no negative experiences on it. This objection may be refuted with a combination of the other problems to be considered. One is the implausibility of pinpointing to all solely bad experiences partitioned wholly from good. Outrage, for example, is uncomfortable, therefore feels negative, but as Mill (2006) and other moral philosophers have noted, it is central to responses to injustice. Other problems include practical issues, such as, whether it is feasible to tease apart, genetically, the experience of pleasure from non-pleasures. Another is the relativity, both individually and culturally, of what is indeed pleasure and pain. Another is the case that poets have often considered over the centuries, and that is whether one really can experience pleasure without there being the contrastive of pain (this issue relates to the practical one of whether pleasure and pain, genetically, physiologically, can be fully teased apart from the body).

\section{References}

Agar, Nicholas. 2010. Humanity's End: Why We Should Reject Radical Enhancement. Cambridge, MA: MIT Press.

Baraclough, T., and E. Herniou. 2003. "Why Do Species Exist? Insights from Sexuals and Asexuals." Zoology 106 (4): 275-282.

Benatar, David. 2006. Better Never To Have Been. Oxford: Oxford University Press.

Blok, Vincent. Forthcoming. "Look Who's Talking: Responsible Innovation, the Paradox of Dialogue and the Voice of the Other in Communication and Negotiating Processes." Journal of Responsible Innovation, published online 18 June 2014. doi:10.1080/23299460.2014.924239.

Bostrom, Nick. 2004. "The Future of Human Evolution." In Death and Anti-death: Two Hundred Years after Kant, Fifty Years after Turing, edited by C. Tandy, 339-371. Palo Alto, CA: Ria University Press.

Bostrom, Nick. 2005. “A History of Transhumanist Thought.” Journal of Evolution and Technology 14 (1): $1-25$.

Bostrom, Nick. 2008. "Why I Want to Be a Posthumanist When I Grow Up." In Medical Enhancement and Posthumanity, edited by B. Gordijn and R. Chadwick, 107-137. New York: Springer.

Bostrom, Nick, and Anders Sandberg. 2008. "The Wisdom of Nature: An Evolutionary Heuristic for Human Enhancement." In Human Enhancement, edited by J. Savulescu and N. Bostrom, 375-416. Oxford: Oxford University Press.

Buchanan, A. 2012. Beyond Humanity? Oxford: Oxford University Press.

Buchanan, Allen, Dan Brock, Norman Daniels, and Daniel Wikler. 2000. From Chance to Choice. Cambridge: Cambridge University Press.

Buchanan, Allen, and R. Powell. 2011. "Breaking Evolution's Chains: The Promise of Deliberate Genetic Manipulation in Humans." Journal of Medicine and Philosophy 36 (1): 116-127.

Chalmers, David. 2010. "The Singularity: A Philosophical Analysis.” Journal of Consciousness Studies 17: 7-65.

Claridge, M., H. Dawah, and R. Wilson, eds. 1997. Species: The Units of Biodiversity. London: Chapman and Hall. 
Darwin, Charles. 1952. "The Origin of Species." In Great books of the Western world, Vol. 49: Darwin, edited by R. Hutchins, 1-251. Chicago: Encyclopedia Britannica.

Dasgupta, P. 1995. "Population, Poverty, and the Local Environment." Scientific American 272 (February): $40-45$.

Dawkins, Richard. 1976. The Selfish Gene. Oxford: Oxford University Press.

Dennett, Daniel. 1995. Darwin's Dangerous Idea. New York: Simon and Schuster.

Depew, D. 2011. "Is Evolutionary Biology Infected with Invalid Teleological Reasoning?" Philosophy \& Theory in Biology 2: e105. doi:10.3998/ptb.6959004.0002.005

Etcoff, N. 1999. Survival of the Prettiest: The Science of Beauty. New York: Doubleday.

Fletcher, Joseph. 1988. The Ethics of Genetic Control: Ending Reproductive Roulette. Buffalo, NY: Prometheus Books.

Freeman, R. Edward. 2008. "Managing for Stakeholders.” In Ethical Issues in Business, edited by T. Donaldson and P.H. Werhane, 39-53. Upper Saddle River, NJ: Pearson Prentice Hall.

Garreau, J. 2005. Radical Evolution: The Promise and Peril of Enhancing Our Minds, Our Bodies - and What It Means to Be Human. New York: Doubleday.

Gould, Stephen, and Richard Lewontin. 1979. "The Spandrels of San Marco and the Panglossian Paradigm: A Critique of the Adaptationist Programme." Proceedings of the Royal Society B: Biological Sciences 205: 581-598.

Guston, David. 2013. "Understanding 'Anticipatory Governance'.” Social Studies of Science, published online November 15, 2013. doi:10.1177/0306312713508669.

Harris, John. 2007. Enhancing Evolution: The Ethical Case for Making Better People. Princeton, NJ: Princeton University Press.

Hauskeller, Michael. 2013. Better Humans? Understanding the Enhancement Project. Durham: Acumen. Hauskeller, Michael. 2014. Sex and the Posthuman Condition. Hampshire, UK: Palgrave Macmillan.

Hey, J. 2001. "The Mind of the Species Problem." Trends in Ecology and Evolution 16: 326-329.

Hoople, Gordon. Forthcoming. "Engineering Ethics in Every Decision." Journal of Responsible Innovation, published online 13 May 2014. doi:10.1080/23299460.2014.922341.

Hughes, John. 2006. "What Comes After Homo sapiens?” New Scientist, Nov. 16: 70-72.

Huxley, Julian. 1957. “Transhumanism.” In New Bottles for New Wine, 13-17. London: Chatto and Windus. Jones, B., A. Little, and D. Perrett. 2003. "Why Are Symmetrical Faces Attractive?" In Advances in Psychology Research, edited by S. Shodov, 145-166. New York: Nova Science.

Kurzweil, Ray. 2005. The singularity is Near: When Humans Transcend Biology. New York: Viking.

Lewontin, Richard. 1972. "The Apportionment of Human Diversity." Evolutionary Biology 6: 391-398.

Lewontin, Richard. 1995. Human Diversity. 2nd ed. New York: Scientific American Library.

Mill, John Stuart. 2006. Utilitarianism. Chicago: Chicago University Press.

Miller, L. F. 2013a. "The Rights of Self-Delimiting Peoples: Protecting Those Who Want No Part of Us." Human Rights Review 14 (1): 31-51.

Miller, L. F. 2013b. "Why Should One Reproduce? The Rationality and Morality of Human Reproduction," Ph.D. thesis, City University of New York Graduate Center.

Miller, L. F. 2014a. "Is Species Integrity a Human Right? A Rights Issue Emerging from Individual Liberties with New Technologies." Human Rights Review 15 (2): 177-199.

Miller, L. F. 2014b. "'We Now Control Our Evolution': Circumventing Ethical and Logical Cul-De-Sacs of an Anticipated Engineering Revolution." Science and Engineering Ethics 20: 1011-1025.

Müller, G. and S. Newman, eds. 2005. "Editorial: Evolutionary Innovation and Morphological Novelty." Journal of Experimental Zoology Part B: Molecular and Developmental Evolution (special issue) 304B: 485-486.

Nordmann, Alfred. 2014. "Responsible Innovation, the Art and Craft of Anticipation." Journal of Responsible Innovation 1 (1): 87-98.

O’Brien, S., D. Wildt, and M. Bush. 1997. "The Cheetah in Genetic Peril.” Scientific American 254: 68-76.

Overall, Christine. 2012. Why Have Children? Cambridge, MA: MIT Press.

Pigliucci, Massimo. 2001. Phenotypic Plasticity: Beyond Nature and Nurture. Baltimore: Johns Hopkins University Press.

Piglucci, Masimo. 2003. "Species as Family Resemblance Concepts: The (Dis-) Solution of the Species Problem?" BioEssays 25: 596-602.

Pigliucci, Massimo, and J. Kaplan. 2006. Making Sense of Evolution: The Conceptual Foundations of Evolutionary Biology. Chicago: University of Chicago Press.

Pinker, Steven. 1997. How the Mind Works. New York: Norton.

Reiss, J. 2009. Not by Design: Retiring Darwin's Watchmaker. Berkeley: University of California Press. 
Savage, J. 1977. Evolution. 3rd ed. New York: Holt, Reinhart, Winston.

Savulescu, Julian. 2001. "Procreative Beneficence; Why We Should Select for the Best Child." Bioethics 15 (5-6): 413-426.

Shiffrin, Seana. 1999. "Wrongful Life, Procreative Responsibility, and the Significance of Harm." Legal Theory 5: 117-148.

United Nations. 2007. United Nations Declaration on the Rights of Indigenous Peoples. New York: United Nations.

Vinge, Vernor. 1993. "The Coming Technological Singularity." Presented at VISION-21 symposium sponsored by NASA. NASA Lewis Research Center and the Ohio Aerospace Institute, March 30-31.

Wilsdon, J. 2014. "From Foresight to Hindsight: The Promise of History in Responsible Innovation." Journal of Responsible Innovation 1 (1): 109-112.

Wilson, Edward O. 1999. Consileince. New York: Random House.

Young, S. 2006. Designer Evolution: A Transhumanist Manifesto. New York: Prometheus. 